\title{
Anaplastic Astroblastoma
}

National Cancer Institute

\section{Source}

National Cancer Institute. Anaplastic Astroblastoma. NCI Thesaurus. Code C84347.

An astroblastoma characterized by the presence of high mitotic activity, cytologic atypia, and architectural distortion. 